\title{
Semifinais das Olimpíadas de Química JúnIor 2010
}

Decorreram no dia 17 de Abril de 2010, em diversas Universidades de norte a sul do país, as semifinais das Olimpíadas de Química Júnior (OQJ). A iniciativa, organizada pela Sociedade Portuguesa de Química (SPQ) em conjunto com diversos Departamentos das Universidades intervenientes, contou com uma forte afluência por parte dos alunos do ensino básico ( $8^{\circ}$ e $9^{\circ}$ anos de escolaridade). Este ano participaram 579 equipas, correspondendo a um total de 1737 alunos, distribuídos da seguinte forma: 161 equipas em Lisboa (Faculdade de Ciências da Universidade de Lisboa, Faculdade de Ciências e Tecnologia da Universidade Nova de Lisboa e Instituto Superior Técnico), 41 equipas no Porto (Faculdade de Ciências da Universidade do Porto), 85 equipas em Aveiro (Universidade de Aveiro), 38 equipas em Faro (Universidade do Algarve), 59 equipas na Covilhã (Universidade da Beira Interior), 69 equipas em Coimbra (Universidade de Coimbra), 75 equipas em Braga (Universidade do Minho) e 51 equipas em Vila Real (Universidade de Trás-os-Montes e Alto Douro).

De uma forma geral, as provas realizadas nas diversas Universidades englobaram uma componente teórica e outra prático-laboratorial. Em várias Universidades, enquanto os alunos participantes se encontravam atarefados na realização das provas, os respectivos Professores acompanhantes foram convidados a participar em actividades ou a assistir a palestras organizadas pelos diferentes departamentos. A título de exemplo, na Universidade do Minho os Professores acompanhantes assistiram às palestras "Química e Imagem Médica", proferida pelo Doutor João Paulo André, e "Química: uma carreira" apresentada pela Doutora Sílvia Pereira Lima. Já na Faculdade de Ciências da Universidade do Porto puderam assistir à palestra "A Química e o Homem" a cargo do Doutor João Paiva. Na Universidade da Beira Interior (UBI) os professores acompanhantes tiveram ao seu dispor uma visita guiada a dois dos núcleos do Museu de Lanifícios da UBI, nome- adamente ao Núcleo da Real Fábrica Veiga/Centro de Interpretação dos Lanifícios (ainda não aberto ao público) e ao Núcleo da Real Fábrica de Panos. Já a Universidade de Coimbra, proporcionou um workshop e palestra a cargo do Clube de Robótica da Faculdade de Ciências e Tecnologia da Universidade de Coimbra, um grupo muito dinâmico que tem ganho muitas competições nacionais e irá participar em eventos internacionais.

Em cada semifinal foram premiadas as 3 melhores equipas (medalhas de "Ouro", "Prata" e "Bronze"). No entanto, apenas passaram as duas melhores equipas à Final Nacional, que se realizou no Departamento de Química da Universidade de Coimbra, no dia 8 de Maio, numa competição colectiva que incluiu uma prova teórica e uma prova prática laboratorial. As equipas vencedoras e seleccionadas para disputar a Final Nacional foram as seguintes:

\section{Faculdade de Ciências da Universida-} DE DE LISBOA

$1^{\circ}$ lugar: Escola Básica dos $2 .^{\circ}$ e $3 .^{\circ}$ Ciclos Professor Egas Moniz (Massamá) - equipa constituída por Ana Marta Afonso, Bruno Sampaio e Tiago Santos, coordenada pela Professora Maria de Fátima D. Martins;

$2^{\circ}$ lugar: Escola Básica dos $2 .^{\circ}$ e $3 .^{\circ}$ Ciclos Professor Egas Moniz (Massamá) - equipa constituída por Catarina Beja, Ji Caiwei e Joana Martins, coordenada pela Professora Maria de Fátima D. Martins;

Faculdade de Ciências e Tecnologia DA Universidade Nova de Lisboa

10 lugar: Externato "Frei Luís de Sousa" (Almada) - equipa constituída por Ana Rita Bello, Francisco António Parente e João Pedro Ferreira, coordenada pelo Professor Miguel Nuno Oliveira;

$2^{\circ}$ lugar: Externato "Frei Luís de Sousa" (Almada) - equipa constituída por Inês Álvaro Franco, Pedro Xavier Coito e Tomás Monteiro Fernandes, coordenada pelo Professor Miguel Nuno Oliveira;
Faculdade de Ciências da UniversidaDE DO PORTO

$1^{\circ}$ lugar: Colégio da Trofa (Trofa) equipa constituída por Afonso João B.C.C. Silva, Francisco A.D. Amorim e Lígia Beatriz S.A. Dias, coordenada pela Professora Cecília Azevedo;

$2^{\circ}$ lugar: Escola Básica dos $2 .^{\circ}$ e $3 .^{\circ}$ Ciclos Dr. Flávio Gonçalves (Póvoa de Varzim) - equipa constituída por Guilherme F.M. Silva, Mariana R. Macieira e Rita S.B. Lima, coordenada pela Professora Helena Maria C.F. Tavares;

\section{INSTITUTO SUPERIOR TÉCNICO}

$1^{\circ}$ lugar: Escola Secundária com 3. Ciclo do Ensino Básico do Restelo (Lisboa) - equipa constituída por João Machado, Luís Magalhães e Sebastião Carvalho, coordenada pela Professora Carla Repsina Santos;

$2^{\circ}$ lugar: Colégio "D. Afonso V" (Mem Martins) - equipa constituída por Joana C.M. Silva, Maria del Pilar B. Simões, José Elísio S. Santos, coordenada pela Professora Maria José G.F.M. Sequeira;

\section{UnIVERSIDAde de AveIRo}

$1^{\circ}$ lugar: Escola Secundária com $3 .^{\circ}$ Ciclo do Ensino Básico de Gouveia (Gouveia) - equipa constituída por João Pedro Silva, Luís Miguel Mimoso e Pedro Miguel Ferreira, coordenada pelo Professor Armando Almeida;

$2^{\circ}$ lugar: Escola Secundária com 3. ${ }^{\circ}$ Ciclo do Ensino Básico Dr. Jaime Magalhães Lima (Esgueira) - equipa constituída por Ana Micaela Nunes, Bárbara Rosário e Diana Carvalho, coordenada pela Professora Isabel Maria T. Branco;

\section{Universidade do Algarve}

$1^{\circ}$ lugar: Escola Básica Integrada com Jardim de Infância de Montenegro (Montenegro) - equipa constituída por Ana Alho, Jessica Jacinto e Sofia Luz, coordenada pela Professora Patrícia Raposo;

$2^{\circ}$ lugar: Escola Básica dos $2 .^{\circ}$ e $3 .^{\circ}$ Ciclos de D. Afonso III (Faro) - equipa constituída por Alexandre Poeira, Ana Rute Baptista e Inês Brigas, coorde- 
nada pela Professora Cláudia Marisa C.D. Neves;

\section{UNIVERSIDADE DA BEIRA INTERIOR}

$1^{\circ}$ lugar: Escola Básica dos $2 .^{\circ}$ e $3 .^{\circ}$ Ciclos Serra da Gardunha (Fundão) equipa constituída por Inês V. Martins, Filipa C.P. Catarro e Vanessa Sofia M. Santos, coordenada pela Professora Maria Júlia G.N. Gil;

$2^{\circ}$ lugar: Escola Básica dos $2 .^{\circ}$ e $3 .^{\circ}$ Ciclos Serra da Gardunha (Fundão) - equipa constituída por Ana Cláudia B. Honório, Ana Rita S.S. Henriques e Laura Soares Ramos, coordenada pela Professora Maria Júlia G.N. Gil;

\section{Universidade de Coimbra}

$1^{\circ}$ lugar: Escola Básica dos $2 .^{\circ}$ e $3 .^{\circ}$ Ciclos com Ensino Secundário do Eng. ${ }^{\circ}$ Dionísio Augusto Cunha (Canas de Senhorim) - equipa constituída por Carolina Fernandes, João Santos e Pedro Peixoto, coordenada pela Professora Maria Teresa C.M. Almeida; $2^{\circ}$ lugar: Escola Básica dos $2 .^{\circ}$ e $3 .^{\circ}$ Ciclos de Eugénio de Castro (Coimbra) - equipa constituída por Bernardo da Silva Alves, João Luís Janela e Rita Gomes Teixeira, coordenada pela Professora Isabel Prata;

\section{Universidade do Minho}

$1^{\circ}$ lugar: Escola Secundária com $3 .^{\circ}$ Ciclo do Ensino Básico de Camilo Castelo Branco (Vila Nova de Famalicão) - equipa constituída por Gonçalo Bem, Luís Costa e Paulo Ribeiro, coordenada pela Professora Rute M.L. Barreto; $2^{\circ}$ lugar: Escola Básica dos $2 .^{\circ}$ e $3 .^{\circ}$ Ciclos de Caldas das Taipas (Guimarães) - equipa constituída por Ana
Catarina Ferreira, Ana Sofia Martinho e João Miguel Gomes, coordenada pela Professora Fernanda Clara M. Ramos;

Universidade de Trás-os-Montes E Alto Douro

$1^{\circ}$ lugar: Escola Básica dos $2 .^{\circ}$ e $3 .^{\circ}$ Ciclos D. Manuel de Faria e Sousa (Felgueiras) - equipa constituída por João Miguel F. Silva, Marcelo F.T. Oliveira, Raquel D.L. Cunha, coordenada pelo Professor Pedro Goucho; $2^{\circ}$ lugar: Colégio "Nossa Senhora da Boavista" (Vila Real) - equipa constituída por Luís Pereira, Patric Ribeiro e Rui Quintelas, coordenada pelos Professores Carlos Manuel Pires e Manuel Soares;

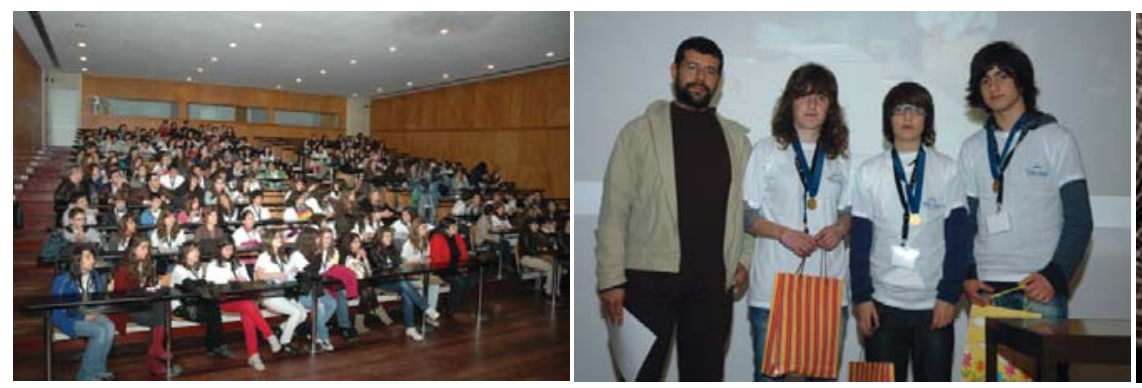

JA
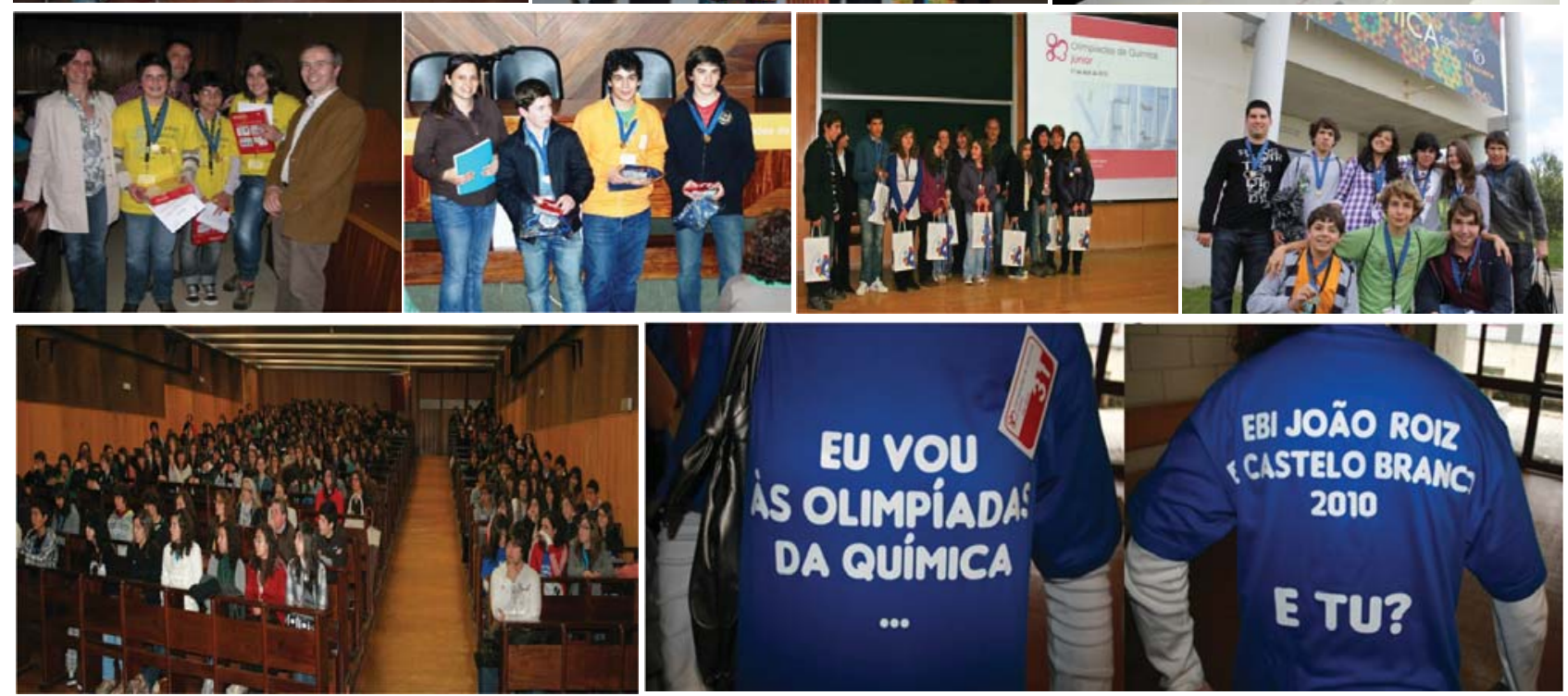

Fotografias de algumas das equipas vencedoras e dos momentos emocionantes vivenciados nas provas e em sessões de recepção dos alunos e de entrega de prémios em diferentes Universidades

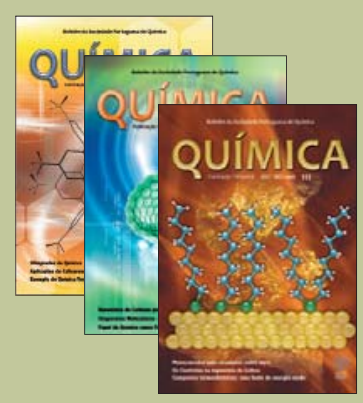

Vamos enRIQUeCER O MUNDO dA Química!

Colabore connosco: envie-nos o seu Artigo, Notícia ou Actualidade E FAÇA PARTE dO CONCEITUADO LEQUE DE AUTORES QUE JÁ ESCREVEU E ESCREVE PARA O QUÍMICA

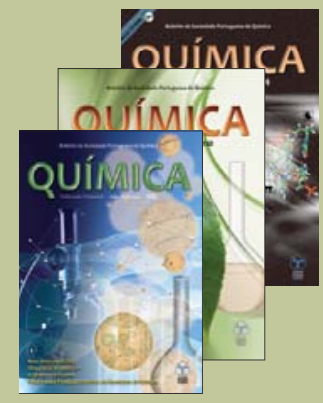

